\title{
A construção do Atlas municipal de Cambira/PR: para o ensino e a aprendizagem Geográfica do lugar
}

\begin{abstract}
Resumo: Um Atlas Municipal Escolar constitui-se em um material didático elaborado sob a concepção de um objeto de ensino que possibilita atingir uma melhor compreensão crítica e reflexiva acerca da realidade local. No entanto, projetos que desenvolvem materiais como este, em linguagem e divisão geográfica local, são escassos no cenário nacional. Baseado nessas premissas, o presente trabalho busca ampliar o conhecimento sobre Atlas municipal e divulgar as técnicas produção de materiais escolares adequados a escala local, assim como apresentar a forma pela qual foi desenvolvido o Atlas municipal de Cambira. 0 projeto desenvolveu-se a partir do Programa Universidade Sem Fronteiras da SETI, baseado em outros trabalhos desenvolvidos no Brasil: como em Limeira -SP, Rio Claro-SP, Itamandiba-MG, São Leopoldo - RS e Maringá - PR. Para o desenvolvimento e construção do Atlas, a base de dados foi retirada de órgãos de fomento do Estado como: (IPARDES, IBGE, ITCG, IAPAR). 0 município de Cambira, contemplado com o projeto, localiza-se na região centro-norte do Paraná, área metropolitana de Maringá, dentro do eixo intermunicipal Jandaia do Sul/Apucarana. Os resultados foram apresentados com a publicação deste material e a utilização do mesmo pelos alunos da rede municipal de ensino e pela população. Os conteúdos abrangidos no Atlas foram divididos em pranchas, cada qual com assuntos relacionados ao município de Cambira, contendo fotos, gráficos, desenhos e mapas. Além do Atlas, a equipe do projeto ainda desenvolveu outras atividades, tais como: oficinas com os professores; entrevista com moradores; trabalhos de campo e reconhecimento geográfico; registro fotográfico, concurso "Desenhando Cambira", e divulgação do projeto por meio de publicações e premiações.
\end{abstract}

\section{The construction of the Atlas municipality of Cambira / PR: for teaching and learning Geographic Place}

\footnotetext{
Abstract: A Municipal School Atlas is in a didactic material prepared under the design of an object of teaching that makes possible to reach a better understanding of critical and reflective about the local reality. However, projects like this to develop materials in local language and geographical division, are scarce on the national scene. Based on these assumptions, this paper seeks to expand knowledge about Atlas municipal and disseminate educational materials production techniques suitable for local, as well as presenting the way in which the Atlas was developed municipal Cambia. The project was developed from the Program University of SETI Sans Frontieres, based on other studies in Brazil, as in Limeira-SP, Rio Claro-SP, Itamandiba-MG, São Leopoldo - RS and Maringá - PR. For the development and construction of the Atlas, the database was drawn from development agencies of the state as: (IPARDES, IBGE, ITCG, IAPAR). The Cambira, awarded the project, located in north-central Paraná, Maringá metropolitan area within the inter-axis Jandaia South / Apucarana. Results are presented after the publication of this material and use thereof by students of municipal schools and the public. The content covered in the Atlas were divided into planks, each with issues related to Cambira with photos, graphs, drawings and maps. In addition to the Atlas, the project team has developed other activities such as workshops with teachers, interviews with residents, fieldwork and geographical reconnaissance, photographic, tender "Drawing Cambia", and disseminating the project through publications and awards.
}

Pedro França Junior*

Victor Pagadigorria Zucchi** $^{\text {** }}$

* Doutorando em Geografia UNESP- Presidente Prudente,

Professor do Departamento de Geografia UNICENTRO, Vila Carli- Guarapuava-PR

** Graduado em Geografia- UEM Universidade Estadual de Maringá

Palavras-chave: Atlas Municipal; Ensino de Geografia; Cambira -PR

Key-Words: Atlas Hall School of Geography; Cambira - PR. 


\section{Introdução}

O objetivo deste trabalho é da busca de ampliar o conhecimento sobre Atlas municipais e divulgar as técnicas produção de materiais escolares adequados a escala local, assim como apresentar a forma pela qual foi desenvolvido o Atlas municipal de Cambira.

O projeto "Atlas Municipal de Cambira" foi desenvolvido por meio do programa: "Universidade Sem Fronteiras" (USF), vinculado à Secretaria de Ciências, Tecnologia e Ensino Superior do Paraná (SETI). Em primeira instância, tratava-se de uma politica de governo, no entanto, devido à sua importância de extensão acadêmica e social, tornou-se um programa que em quatro anos vem atuou em projetos de extensão universitária reafirmando o compromisso social e o papel humanista da Universidade. No Paraná foram 427 projetos envolvendo 3.624 bolsistas em 280 municípios, com um repasse de $\mathrm{R} \$ 14.213 .645,00$. Trata-se do maior programa de extensão universitária do Brasil.

Até o presente momento, muito já se fez através deste programa, visto que o mesmo contempla os municípios com baixos índices de IDH (Índice de Desenvolvimento Humano) do estado do Paraná. Nos projetos escolhidos, somam-se as necessidades da comunidade com a disponibilidade da rede acadêmica em desenvolver o projeto.

$O$ departamento de Geografia da Universidade Estadual de Maringá sempre demonstrou um grande interesse em participar e desenvolver um destes projetos do programa Universidade Sem Fronteiras. A partir daí, somou-se a este, o interesse e a receptividade da Prefeitura Municipal de Cambira, principalmente da Secretaria de Educação do município, que por meio da secretária e professora Ms. Dóris de Jesus Lucas Moya, que contribuiu para que este projeto fosse iniciado. A Universidade concebeu todo o apoio logístico e profissional necessário para a realização do projeto, enquanto o Município de Cambira contribuiu com grande receptibilidade e disponibilidade dos moradores, professores das escolas públicas e funcionários da Secretaria de Educação em atender os acadêmicos e professores da Universidade Estadual de Maringá, envolvidos no projeto. No que tange aos recursos financeiros, a Secretaria de Ciência e Tecnologia e ensino superior (SETI)

${ }^{1}$ Coordenadora:ProfessoraDr. Angela Maria Endlich

2ProfessoresdoDepartamento de Geografia UEM:Dr. Elza YassukoPassini, Dr. Deise Regina Queiroz, Dr. Cezar Miranda Mendes, Ms. Américo José Marques, e Ms. Yolanda ShizueAoki;

${ }^{3}$ RecémFormado:PedroFrança Junior

${ }^{4}$ AlunosGraduandos:AlexPires Boava, Lorena Pereira da Silva, TatianaMayumiTamura,Vinicius Rafael da Conceição, Vitor PagadigorriaZucchi.

${ }^{5}$ Pedro Henrique Carnevalli Fernandes, Thiago César F.

Geografia Ensino\&:Pesquisa, v. 17, n.1 p. 161-172, jan./abr. 2013

Atlas municipal de Cambira/PR: Construindo Conhecimentos Geográficos

162

ISSN 2236-4994 pontuou os repasses, para pagamentos de pessoal, compra de equipamentos, e impressão gráfica.

A equipe do projeto "Atlas Municipal de Cambira" contou com 1 (uma) professora coordenadora $^{1} ; 5$ (cinco) professores ${ }^{2}, 1$ (um) aluno recém formado ${ }^{3}, 5$ alunos de graduação ${ }^{4}$ e 2 (dois) alunos colaboradores ${ }^{5}$, juntamente com 0 apoio da Universidade. 0 êxito na produção deste material cabe-se à dedicação da equipe, que buscou durante todo o processo de elaboração do Atlas melhorar o conteúdo apresentado, garantindo a interação dos assuntos tratados com o futuro usuário do material didático, os alunos da rede municipal de Cambira-PR.

O objetivo principal deste projeto foi produzir um Atlas com dados geográficos significativos e atualizados do município de Cambira, além de contribuir para a produção de materiais escolares adequados à escala local. Além disso, este projeto provém da tentativa de atender a demanda de conteúdo programático da disciplina de Geografia, articulando de forma dinâmica e interativa conhecimentos sobre a Geografia do Município de Cambira e os conhecimentos curriculares educacionais propostos pelos documentos oficiais PCN (Parâmetros Curriculares Nacionais de Geografia), (BRASIL, 1997) e Diretrizes Curriculares da Educação Básica do Estado do Paraná: Geografia - DCE (PARANA, 2008).

O desenvolvimento de pesquisas que tratam da problemática relacionada ao ensino da cartografia para escolares tem contribuído de maneira significativa no sentido de fundamentar práticas de ensino apropriadas. A elaboração deste atlas tem como objetivo suprir, ainda que em parte, esta necessidade.

Desta maneira, o Atlas Municipal de Cambira é um material composto por mapas, imagens, gráficos, tabelas, e conteúdos escritos que se referem à história, população, economia, características físicas e paisagens do município. Além disso, ainda possui uma seção que pretende inserir valores de educação ambiental no leitor, trazendo à tona a importância em se preservar as características e qualidades do meio ambiente e enfatizando a responsabilidade dos cidadãos nesta tarefa. 
A partir da leitura deste material, os usuários passarão a ter conhecimento sobre o processo histórico de ocupação do município, as condições ambientais, a participação da área rural e da área urbana na economia do município, os fluxos de pessoas e mercadorias, entre outros assuntos que caracterizam o município de Cambira.

\section{Atlas Escolares Municipais: conceitos e reflexões}

O ensino de geografia na escola deve ser conduzido por meio do acesso dos alunos ao conhecimento produzido pela humanidade, para que possam entender o mundo em que vivem. Receber uma informação, conseguir entendê-la e contextualizar os fenômenos no conjunto do mundo globalizado e finalmente compreender o lugar como fruto da reprodução desses processos em determinados tempos e espaços, é um grande objetivo. Outro importante objetivo pauta-se na necessidade de fazer com que o aluno compreenda o seu papel neste processo de construção do espaço, tendo condições de construir a sua identidade e pertencimento.

Assim Callai (2002) afirma que o estudo das características geográficas de um lugar, considerando as diferentes escalas de análise, tem como o suporte 0 desenvolvimento de habilidades específicas associado à construção de novos conceitos. Esta pode ser uma alternativa de aprendizado da Geografia e de se construir como sujeito de sua historia ao tempo, produzindo o espaço como sujeito social.

A mesma autora relata:

\begin{abstract}
"O aluno ao ler o espaço, desencadeia-se o processo de conhecimento da realidade que é vivida cotidianamente. Constrói-se o conceito, que é uma abstração da realidade em si, a partir da compreensão do lugar concreto, de onde se extraem elementos para pensar o mundo (ao construir a nossa história e o nosso espaço). Nesse caminho, ao observar o lugar especifico e confrontá-lo com outros lugares, tem inicio o processo de abstração que se assenta entre o real aparente, visível, perceptível e o concreto pensado na elaboração do que está sendo vivido." (Callai, 2005: p. 241)
\end{abstract}

Carreiro (2003) salienta que o uso de mapas no ensino possibilita duas formas de construção de conhecimentos: a primeira é de conceber o ensino como transmissão de conteúdos, o que gera uma relação de exterioridade com as informações contidas nos mapas municipais; a segunda é de conceber o ensino como construção coletiva de conhecimentos, que possibilita uma aprendizagem significativa para os alunos.

Além de conter informações importantes e precisas sobre as características geográficas do município, o Atlas Municipal desperta nos usuários um sentimento de pertencimento do lugar, através dos demais conteúdos abrangidos.

Conhecer algumas definições sobre o que é um Atlas, é essencial para o entendimento de sua estrutura. Alguns autores conceituam-no de forma simples, sendo o atlas uma coleção de mapas, gráficos, fotos, imagens, de um determinado local. Por outro lado, autores como Carreiro (2003), Le Sann e Almeida (2003), Martinelli (2008) e IBGE (2010) apresentam outras conceituações:

Carreiro (2003) Salienta que:
... Atlas Municipal Escolar se constitui em um material didático elaborado sob a concepção de ensino que pode levar a uma melhor compreensão crítica e reflexiva acerca da realidade local (CARREIRO, 2003 pag. 172).
GeografiaEnsino\& Pesquisa, v. 17, n.1 p. 161-172 jan./abr. 2013

França Junior P.; Zucchi, V. P.

ISSN 2236-4994 I 163 
Para Le Sann e Almeida (2003)

"Um Atlas pode ser definido como uma publicação formada por um conjunto de mapas acompanhada, ou não, de diagramas, textos explicativos, glossário, bibliografia e outros documentos anexos, tais como bandeiras, informações a respeito de alguns países ou orientações sobre como usá-lo. Os Atlas podem ser mundiais, regionais, nacionais, escolares ou ainda, temáticos (climático, de vegetação, da fauna...)".....(LE SANN e ALMEIDA, 2003 pag. 6).

Para Martinelli, 2008

A concepção de um atlas geográfico para escolares tem como proposta básica, a de não ser apenas uma coletânea de mapas, prontos e acabados, mas sim, de compor uma organização sistemática de representações trabalhadas com finalidade intelectual específica. Para a sua coordenação, considera-se o entrelaçamento de duas orientações básicas: o "ensino do mapa", lastreado nas posturas teórico-metodológicas sobre a construção da noção de espaço e respectiva representação, pela criança e o "ensino pelo mapa", baseado na promoção do conhecimento do mundo através dos maาpas, a partir do próximo, vivenciado e conhecido - o lugar ao distante desconhecido - o espaço mundial. 0 conteúdo temático se fundamenta numa lucubração básica do con-hecimento geográfico: a natureza em composição com a sociedade (MARTINELLI, 2008, p. 21).

IBGE/ TEEN, 2010

É um conjunto de mapas ou cartas geográficas. Porem, o termo também se aplica a um conjunto de dados sobre determinado assunto, sistematicamente organizados e servindo de referencia para a construção de informações de acordo com a necessidade do usuário. A palavra Atlas é inspirada na mitologia grega, que narra a história do titã Atlas. Conta-se que Atlas formou frente das batalhas de Cronos e dos Titãs contra os deuses do Olimpo, deixando Zeus furioso. Como castigo, foi obrigado a carregar o mundo nas costas, para sempre....(IBGE, 2010, pag. 1).

Enfim, o atlas é um material didático que auxilia os professores no ensinamento dos lugares, dos territórios, das diferentes regiões, interconectados nas redes e, portanto, configurados numa paisagem própria. Os Atlas atuais são, extremamente complexos, com informações cada vez mais concisas, enriquecidos por uma infinidade de ferramentas que possibilitam a transmissão de informações, como imagens, gráficos, tabelas, croquis, entre outras. Isto representa um intenso processo de evolução da geografia no decorrer dos tempos.

\section{Métodos e técnicas}

As técnicas utilizadas para a confecção do Atlas Escolar de Cambira foram baseadas em trabalhos similares desenvolvidos em outros locais: Redondano (2000) desenvolveu o Atlas geográfico do município de Limeira- SP; Le Sann (2002) organizou a produção do Atlas escolar de Itamarandiba-MG; e Passini (2006) em Maringá, cidade mais próxima a Cambira, desenvolveu 0 "Atlas escolar de Maringá: ambiente e educação" abordando as questões ambientais e socioeconômicas do Município. Neste mesmo segmento de atlas escolares, existem outros materiais, mas de abrangência estadual, nacional e mundial, que compartilham do mesmo objetivo, porém com escalas de análise maiores. Como por exemplo, podemos citar os atlas elaborados por Maria Elena Simielli e IBGE para o Brasil, em diversas edições.

Geografia Ensino\&Pesquisa, v. 17, n.1 p. 161-172, jan./abr. 2013

Atlas municipal de Cambira/PR: Construindo Conhecimentos Geográficos

164

ISSN 2236-4994
$O$ atlas escolar municipal diferencia-se dos convencionais em dois principais aspectos: primeiramente pelo fato de possuir concepção metodológica de trabalho didático e por seu aspecto estético/artístico; e num segundo momento por direcionar o conhecimento e todas as características ao município escolhido.

Ao utilizar o atlas escolar municipal, o usuário passa a entender as características geográficas de seu município relacionando as informações com as figuras que representam o lugar. A partir 
desta prática o leitor torna-se apto para interpretar mapas, gráficos, tabelas, imagens, croquis e textos, e automaticamente relacioná-los garantindo uma maior compreensão da geografia local. Com estas analogias, o usuário interpretará os códigos, a organização dos objetos e a realidade representada. Na figura 2, verifica-se a conexão entre o usuário e a compreensão geográfica, a partir da observação e interpretação dos conteúdos do lugar.

A base de dados geográficos foi extraída de órgãos públicos tais como: ITCG (Instituto de Terras Cartografia e Geodésia); IBGE (Instituto Brasileiro de Geografia e Estatística); IPARDES (Instituto Paranaense de Desenvolvimento Econômico e Social); IAPAR (Instituto Agronômico do Paraná); SIMEPAR (Sistema Meteorológico do Paraná).

A elaboração dos conteúdos abrangidos no Atlas se deu através da leitura de materiais pertinentes ao município de Cambira e também a partir de dados levantados durante as visitas realizadas pelos professores e alunos participantes do projeto. A partir desses dados elaboraram-se os mapas, textos, gráficos e demais recursos do Atlas.

Figura 2- Conexões entre o usuário e o atlas

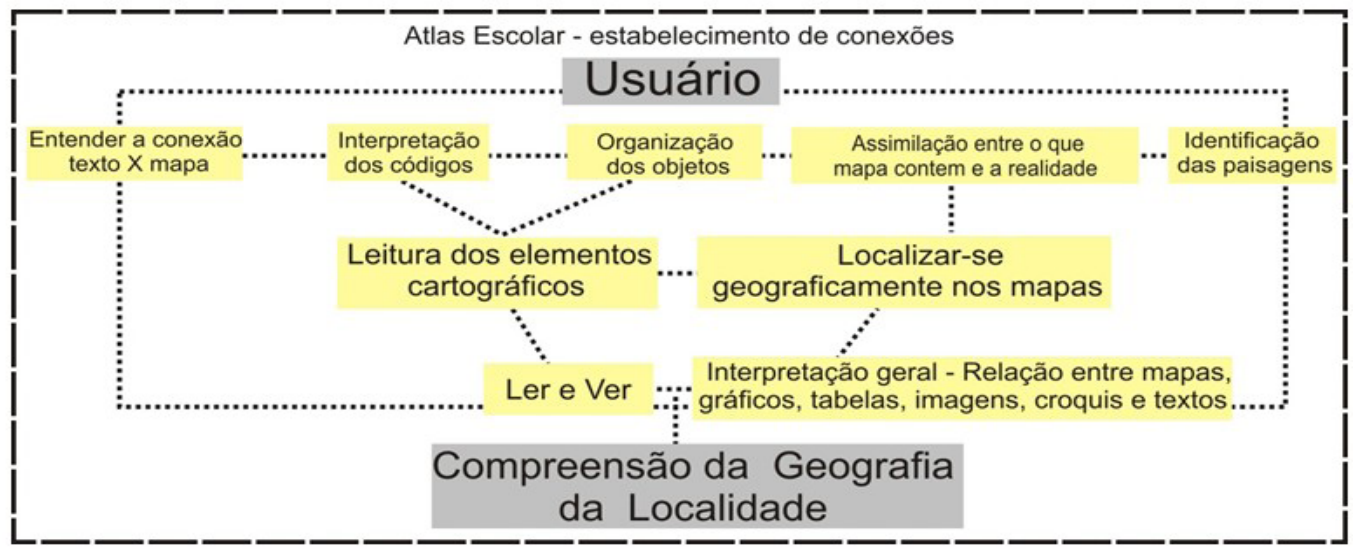

Fonte: Equipe do Projeto, 2010

\section{Desenvolvimento do projeto}

Os resultados compreendem na publicação do material e na forma como foi desenvolvido. 0 atlas foi dividido em pranchas com conteúdos específicos, formatados numa mesma padronização, assim como Passini (2006) desenvolveu no Atlas de Maringá. Cada prancha possui um conteúdo geral e subtítulos para melhor interpretação dos conteúdos. No quadro abaixo, segue as pranchas desenvolvidas, conteúdos, objetivos e as ilustrações divididas em: mapas, gráficos, desenhos, fotos, e croquis.

Este material foi elaborado numa perspectiva que propõe a interação com o usuário, considerados parceiros na investigação da Geografia do lugar. As informações para base de referência devem ser necessariamente objetivas, reais e atualizadas, baseadas em dados de órgãos de fomento.

As informações retiradas de cartas, fotografias, fotos aéreas, documentos, textos jornalísticos e acadêmicos, transcrições de entrevistas e depoimentos, contribuíram para amarração de assuntos e a configuração dos textos e mapas.

Os conteúdos abordados pelo material didático foram selecionados no decorrer do projeto. Entretanto, outros surgiram no processo de desenvolvimento, durante a aplicação de pré-testes após a confecção de uma primeira versão.

\section{a. Oficinas com os professores}

No decorrer do projeto as oficinas realizadas com os professores da rede municipal de ensino de Cambira foram fundamentais para que pudessem conhecer um pouco mais sobre o que é um atlas, como foi construído este material e de que maneira os conteúdos deveriam ser trabalhado com os alunos. No total, quatro oficinas foram realizadas.

GeografiaEnsino \& Pesquisa, v. 17,n.1 p. 161-172 jan./abr. 2013

França Junior P.; Zucchi, V. P.

ISSN 2236-4994 165 
As oficinas foram divididas em etapas, cada uma com um objetivo específico. Na primeira oficina apresentou-se o projeto do Atlas para os professores, esclarecendo como o material seria produzido, a fim de entender as técnicas, material e conteúdos.

$\mathrm{Na}$ segunda oficina apresentaram-se as pranchas com seus respectivos objetivos e justificativas. Cada aluno do projeto ficou responsável por apresentar os temas desenvolvidos e explicar como estes deveriam ser trabalhados com os alunos. Neste mesmo dia a equipe do projeto trabalhou com os professores da rede municipal de ensino a elaboração de alguns mapas para que posteriormente pudessem ser trabalhados com os alunos.

Numa terceira oficina, desenvolveu-se um trabalho ensinando aos professores a técnica de construir uma maquete do relevo do município de Cambira, utilizando cartolina, EVA, tesoura, canetas coloridas e cola. A sala foi divida em equipes de cinco membros, onde cada equipe deveria montar sua maquete. Os alunos do projeto auxiliaram os professores e os resultados foram bastante satisfatórios, tanto pelo interesse demonstrado pelos professores quanto pela interação entre eles e a equipe do projeto (Fig. 3).

Figura 3- Oficinas com os professores da rede municipal de educação

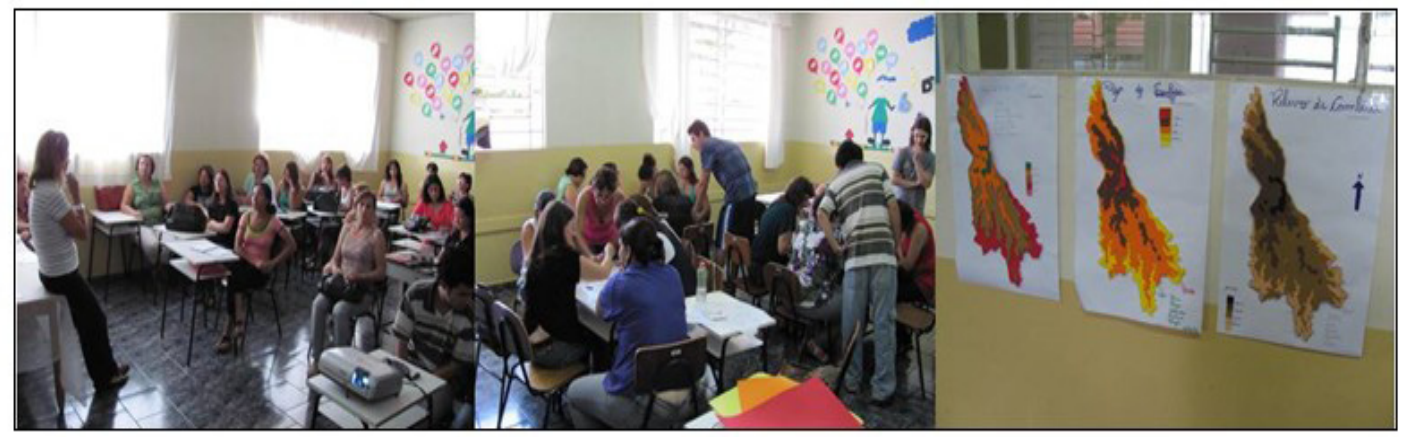

Fonte: Equipe do Atlas, 2010

$\mathrm{Na}$ quarta oficina trabalhou-se com os professores algumas noções de cartografia e de elementos de mapas, como legenda, escala fonte, título, base e coordenadas. Os professores da equipe do projeto apresentaram diversas formas de mapas e diferenças de escalas, demonstrando formas de representação. A partir desta oficina os professores da rede de ensino municipal adquiriram uma noção de como é possível representar a realidade dos diferentes locais numa folha de papel, mantendo as proporções reais através da adequação de escalas.

\section{b. Entrevistas com os moradores locais}

As entrevistas foram realizadas com habitantes locais, que retrataram suas histórias de vida no município, os fatores que os levaram a escolher Cambira como cidade para residir, assim como o que mais se identificam com o município.

Figura 4- Entrevistas com moradores do município de Cambira

Geografia Ensino \& Pesquisa, v. 17, n.1 p. 161-172, jan./abr. 2013

Atlas municipal de Cambira/PR: Construindo Conhecimentos Geográficos

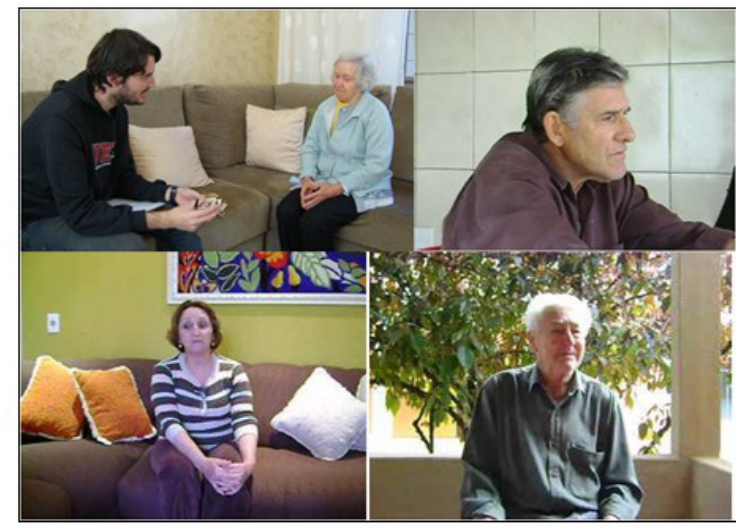

Fonte: Equipe do Atlas, 2010 
Como o Atlas é composto por conteúdos direcionados ao município de Cambira, alguns moradores locais preocupados com a base histórica e cultural do município que seria apresentada no material mostraram-se interessados em participar e contribuir para a elaboração deste conteúdo. Para isso, acompanharam a equipe do projeto em visitas a locais históricos como a Estação Ferroviária e pequenos museus que retratam passagens e utensílios dos pioneiros da região, além de contribuírem com suas experiências de vida, contando um pouco mais sobre a história do município.

Este contato foi muito importante, pois a partir desta etapa a equipe do projeto teve conhecimento da importância que os moradores locais davam aos pioneiros e desbravadores da região. Constatou-se também, a grande singularidade do poder político, cada partido apresentando linhas diferentes e embates políticos de administração.

Figura 5- Trabalhos de campo e visita a locais históricos e geográficos

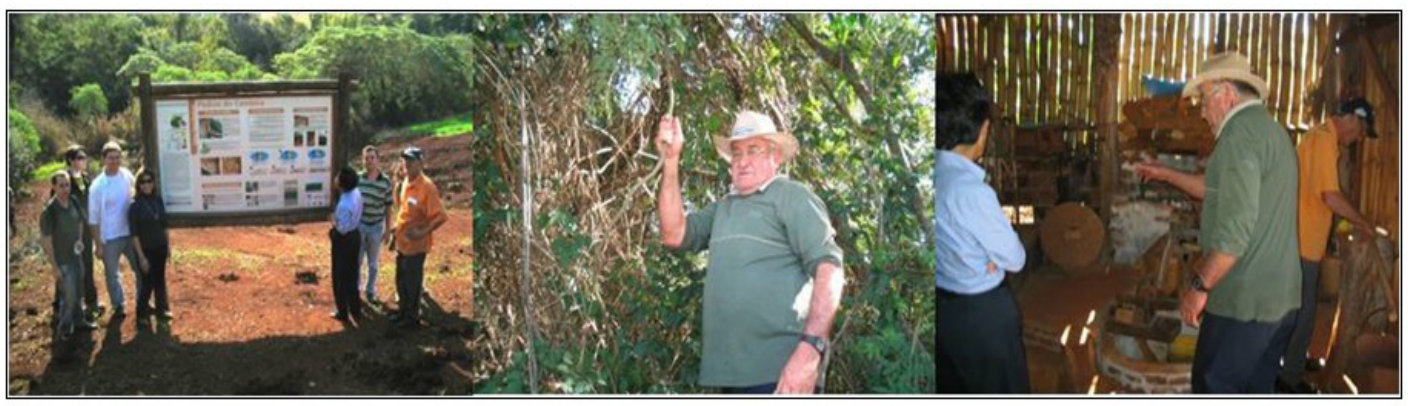

Fonte: Equipe do Atlas, 2010

\section{c. Trabalhos em Campo e registros Fotográficos}

Nos primeiros meses desenvolveu-se o levantamento de dados geográficos sobre Cambira a partir de trabalhos em campo, coleta de pontos georreferênciados e registro de fotografias de diversas localidades do município.

Figura 6- Pontos visitados, pontuados e fotografados.
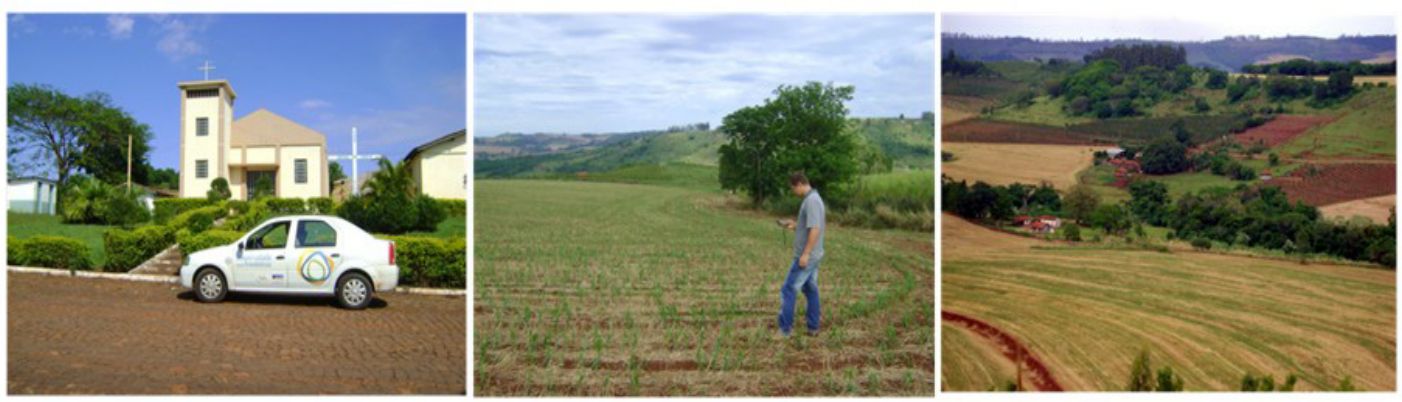

Fonte: Equipe do Atlas, 2010

\section{d. Concurso: "Desenhando Cambira"}

No decorrer do projeto foi apresentada a proposta do concurso "Desenhando Cambira", um concurso de desenhos que tinha como objetivo de integrar os alunos da rede municipal de ensino na tarefa de representar como eles veem o município de Cambira. A proposta foi aceita e elaborou-se este concurso para que a inserção de desenhos desenvolvidos pelas crianças dos colégios municipais fizesse com que elas percebessem sua participação na produção do Atlas (fig. 10). 
Figura 7- Desenhos do concurso "Desenhando Cambira" promovido pela Secretaria de Educação de Cambira e pela equipe do projeto.

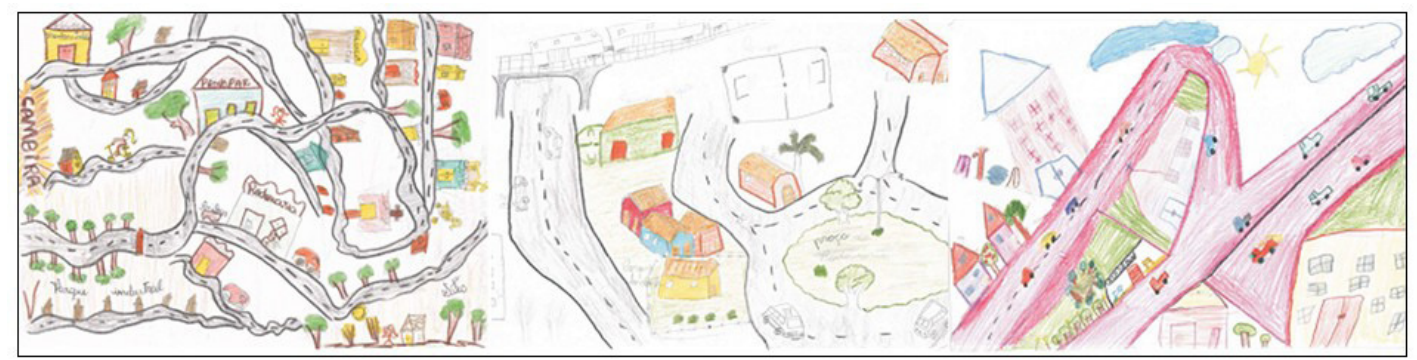

Fonte: Secretaria da educação de Cambira, 2010

\section{e. Publicações e Premiações}

Foram publicados no decorrer do projeto, 1 (uma) monografia: Carnevalli, (2009); 3 (três) trabalhos completos: França Junior et al (2009); França Junior e Malysz (2010); França Junior, (2010) 1 (um) painel: França Junior et al (2010) e relatos de experiência em revista de circulação nacional: Endlich (2010).

O projeto foi também foi contemplado com uma premiação por ter participado de um evento promovido pela SETI (Secretaria de Estado Ciência e Tecnologia). Este prêmio é fruto da dedicação e interesse do aluno Pedro França Junior, recém-formado no curso de Geografia, que no decorrer do projeto desenvolveu parte das atividades pertinentes à elaboração do Atlas, finalizando este trabalho com a publicação de um resumo expandido retratando o desenvolvimento do projeto e sua importância para a sociedade. 0 trabalho foi contemplado com a premiação de $2^{\circ}$ lugar entre todos os projetos "Universidade Sem Fronteiras" do Estado do Paraná, na categoria de artigo acadêmico.

Desde o inicio do programa, coube ao aluno recém-formado ter a liberdade e dinamismo para tomar decisões e articular o desenvolvimento de algumas partes do material, responsabilizando-se por tarefas práticas, teóricas e algumas de cunho burocráticas relacionadas ao projeto.

Figura 8- Premiação do aluno recém-formado, do projeto Produção do Atlas municipal de Cambira (ex-reitor da UEM: Décio Sperandio, Recém-formado: Pedro França Junior, e a ex-secretária da SETI: Ligia Lumina Pupatto) Fonte: SETI-PR/2010

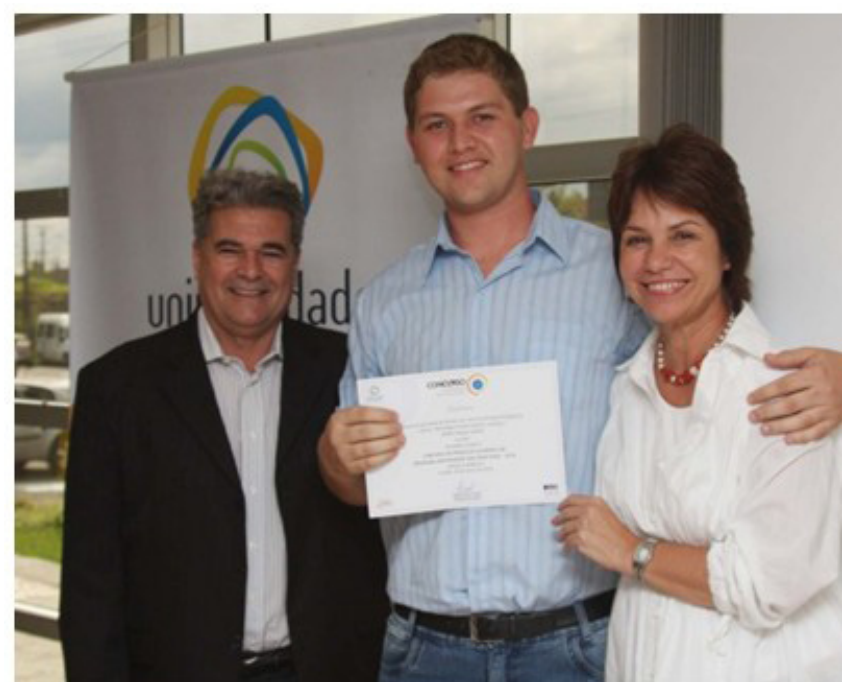

GeografiaEnsino\&Pesquisa, v. 17, n.1 p. 161-172, jan./abr. 2013

Atlas municipal de Cambira/PR: Construindo Conhecimentos Geográficos

168

ISSN 2236-4994

\section{Considerações Finais}

Um atlas municipal é significativo para toda a sociedade local e especialmente para os alunos do ensino fundamental, que serão neste caso os mais beneficiados com a utilização deste material. Entende-se que trabalhar de forma efetiva com a escala local permite uma compreensão 
mais ampla da própria realidade cotidiana. Entretanto, poucos são os materiais disponíveis e adequados para este trabalho.

Dessa forma, o desenvolvimento de pesquisas que tratam a problemática relacionada ao ensino da cartografia nas escolas tem contribuído de maneira significativa no sentido de fundamentar práticas de ensino apropriadas. A elaboração deste atlas tem como objetivo suprir, ainda que em parte, esta necessidade.

Como todo trabalho, este foi difícil para se considerar finalizado, principalmente porque decorreu de um trabalho coletivo construído em circunstâncias marcadas por um cotidiano acelerado pelas múltiplas atividades que se desenvolviam na Universidade Estadual de Maringá concomitante ao período de elaboração do projeto.

Contudo, entende-se este trabalho como uma etapa na melhoria das técnicas e no desenvolvimento de materiais na área do ensino. Desta maneira, o Atlas Municipal de Cambira surge como um material que contribuirá de maneira efetiva para o aprendizado e aprimoramento do conhecimento dos usuários, fazendo-os compreender e conhecer mais detalhadamente o local onde vivem e sentirem-se parte integrante do município de Cambira.

A partir dos resultados verificados pela publicação e uso deste material será possível, posteriormente, desenvolver outros materiais que deem apoio ao Atlas de Cambira, auxiliando e construindo o processo e as dinâmicas de ensino, assim como desenvolver outros Atlas Municipais adequados à realidade de municípios contemplados. Espera-se que programas como o "Universidade Sem Fronteiras" possam ter uma sequência para que possamos prosseguir com novos projetos e atender a demandas de outros municípios, dando continuidade aos trabalhos acadêmicos de extensão social, contribuindo para a melhoria da qualidade de ensino dos locais pesquisados.

\section{Agradecimentos}

Gostaríamos de agradecer a SETI/PR por meio da ex-secretária de Ciência e Tecnologia Ligia Pupatto, por organizar o maior programa de extensão do Brasil: Universidade Sem Fronteiras do estado do Paraná. A Universidade Estadual de Maringá; ao departamento de Geografia, e aos professores, alunos, que participaram do projeto, e em especial ao município de Cambira, por ceder espaços de diálogos com os professores e alunos da rede municipal de ensino, para que o projeto tivesse êxito em suas abordagens.

\section{Referências bibliográficas}

BRASIL, Secretaria de Educação Fundamental. Parâmetros Curriculares Nacionais: historia e geografia/ Secretaria de Educação Fundamental. - Brasília: MEC/SEF, 1997.

CARNEVALLI, P. H. F. Município de Cambira (PR): Desenvolvimento local num contexto regional. Monografia (TCC) Departamento de Geografia UEM, Maringá-PR, 2009.

CARREIRO, Maria Silvia Almeida. Um Olhar Geográfico Sobre a Construção do Atlas Municipal e Escolar de Rio Claro. Cad. Cedes, Campinas, v. 23, n. 60, p. 169-178, agosto 2003.

CALLAI, Helena Copetti. Estudar o lugar para estudar o mundo.In.: Castrogiovanni, Antonio Carlos. (Org.). Ensino de geografia, práticas e textualizações no cotidiano Porto Alegre: Editora Mediação, 2002. p.83-134.

GeografiaEnsino \& Pesquisa, v. 17,n.1 p. 161-172 jan./abr. 2013

França Junior P.; Zucchi, V. P. 
Aprendendo A ler o mundo: a geografia nos anos iniciais do ensino fundamental. In:Educação Geográfica e as teorias de aprendizagens. Caderno CEDES 66. Campinas, vol25, n.66, p. maio/ago. 2005. p. 227-247

ENDLICH, A. M. Projeto Universidade Sem Fronteiras: Atlas Escolar de Cambira-PR. Boletim de Geografia, UEM. Notas, Vol. 28, N01, p. 179-180. Maringá -PR, 2010.

FRANÇA JUNIOR, P. et al. Cartografia e ensino: a elaboração do atlas municipal de Cambira-PR. Anais do I Simpósio Nacional de Recursos Tecnológicos Aplicados à Cartografia e XVIII Semana de Geografia ISSN- 2175-5965. Maringá, 2009.

FRANÇA JUNIOR, P. Atlas Escolar de Cambira-PR: Construindo conhecimentos geográficos. In. Concurso de Produção Acadêmica do Programa Universidade Sem Fronteiras (SETI). Curitiba09 de março de 2010. (Premiação $2^{\circ}$ lugar no Paraná).

FRANÇA JUNIOR, P; MALYSZ, S. T. Observações sensíveis do tempo atmosférico: uma ferramenta para o ensino de climatologia. Anais: II Simpósio Paranaense de Estudos Climáticos e XIX Semana de Geografia. Maringá, 20 a 24 de setembro de 2010. ISSN.2178-1966.

FRANÇA JUNIOR, P; SILVA, L. P; PASSINI, E. Y; ENDLICH, A. M. Atlas escolar de Cambira-PR: construindo conhecimentos geográficos. Resumo dos Anais do $8^{\circ}$ fórum de extensão e cultura da UEM. Maringá, 2010.

IBGE - Instituto Brasileiro de Geografia e Estatística/ SIDRA, disponível em: http://www.sidra.ibge.gov.br/ acesso em 18 de junho de 2009.

IBGE /TEEN- Disponível em: http://www.ibge.gov.br/ibgeteen/atlas acesso em 05/2010

IPARDES - Instituto Paranaense de Desenvolvimento Econômico e Social: disponível: http://www.ipardes.gov.br/modules/conteudo/conteudo.php?conteudo $=6$ acesso em 18 de junho de 2009.

ITCG- INSTITUTO DE TERRAS CARTOGRAFIA E GEOCIÊNCIAS. Disponível em http://www. itcg.pr.gov.brl, acesso fevereiro de 2010.

IAPAR- INSTITUTO AGRONÔMICO DO PARANÁ- Disponível em www.iapar.brl, acesso em fevereiro de 2010.

LE SANN, Janine Gisèle. Atlas escolar de Itamarandiba. Rio Claro, 2002.

LE SANN, Janine Gisèle; ALMEIDA, Rosangela Doin de. Cartografia na Escola. TVE BRASIL, PGM- Atlas Escolares, pag. 1-8, 2003. Disponível em www.tvebrasil.com.br/salto/boletins2003/, acesso em junho de 2009.

MINEROPAR, MINERAIS DO PARANÁ Disponível em www.mineropar.pr.gov.brl, acesso em fevereiro de 2010.

Geografia Ensino\&Pesquisa,v.17, n.1 p. 161-172, jan./abr. 2013

Atlas municipal de Cambira/PR: Construindo Conhecimentos Geográficos

170

ISSN 2236-4994
OLIVEIRA, Adriano Rodrigo. 0 Uso de Atlas Municipais Escolares e as Formas de Construção do Conhecimento em Sala de Aula: Analisando Situações de Ensino. Cad. Cedes, Campinas, v. 23, n. 60, p. 218-230, agosto 2003.

PASSINI, Elza Yasuko. Atlas escolar de Maringá: ambiente e educação. 124 p. Maringá: Eduem, 2006. 
PARANÁ, Secretaria de Estado da Educação do Paraná. Diretrizes Curriculares da Educação Básica: Geografia. Paraná, 2008. 100p.

REDONDANO, Dynoráh Cappi; e outros. Atlas municipal escolar. $1^{\mathrm{a}}$ ed. Limeira, São Paulo. 2000.

SETI/PR- Secretaria de CiênciasTecnologia e Ensino Superior disponível em: http://www.seti. pr.gov.br/modules/noticias/article.php?storyid=1493 acesso em 05/2011

SIMEPAR- SISTEMA METEOROLÓGICO DO PARANÁ, disponível em www.simepar.brl acesso em fevereiro de 2010.

SIMIELLI, Maria Elena. Geoatlas. São Paulo: Ática, 2000.

\section{Correspondência:}

Pedro França Junior- Universidade Estadual do Centro-Oeste, Setor de Ciências Agrárias e Ambientais- Departamento de Geografia. Rua Simeão Camargo Varela de Sá n. 03. Vila Cascavel. Cep. 85040-080 - Guarapuava, PR - Brasil

E-mail: francapedro2000@yahoo.com.br

Recebido em 30 de julho de 2012.

Revisado pelo autor em 17 de janeiro de 2013.

Aceito para publicação em 23 de janeiro de 2013 